\title{
Human Methamphetamine Pharmacokinetics Simulated in the Rat: Single Daily Intravenous Administration Reveals Elements of Sensitization and Tolerance
}

\author{
David S Segal*,I and Ronald Kuczenski' \\ 'Department of Psychiatry, University of California San Diego School of Medicine, La Jolla, CA, USA
}

\begin{abstract}
We developed a computer-controlled intravenous methamphetamine (METH) administration procedure (dynamic infusion), which enables us to compensate for an important pharmacokinetic difference between rats and humans by imposing a 12 -h half-life for the drug in rats. Dynamic infusion of $0.5 \mathrm{mg} / \mathrm{kg}$ METH produced a pharmacokinetic profile that closely simulates the METH exposure pattern in humans, including an apparent half-life of $11.6 \pm 1.3 \mathrm{~h}$, and an area under the concentration vs time curve of $9.4 \mu \mathrm{Mh}$, about 20-fold larger than results obtained with typical rat pharmacokinetics. Using this procedure, METH produced a prolonged behavioral stimulation and elevation in caudate extracellular dopamine (DA). Both the behavioral and the DA effects exhibited tolerance to the sustained plasma METH exposure. Single daily dynamic infusion of $0.5 \mathrm{mg} / \mathrm{kg}$ METH for 15 days resulted in a progressive enhancement of the behavioral response until about Day 10. On subsequent days, in addition to continued evidence of sensitization, tolerance in the form of a marked decrease in the duration of the behavioral activation became a prominent feature of the response. Qualitative changes in the behavior also emerged. Resumption of METH treatment following 4 days of withdrawal revealed that sensitization was apparent during the first dynamic infusion, and that tolerance re-emerged within two additional days of drug administration. These results showed that a humanlike METH exposure pattern produced behavioral and striatal DA response profiles that are both quantitatively and qualitatively different from the effects typically observed with single daily METH injections in rats. Thus, simulation of human METH exposure patterns may be a critical prerequisite to identifying mechanisms relevant to the chronic use of this drug in humans.

Neuropsychopharmacology (2006) 31, 94I-955. doi: I0.1038/sj.npp. I300865; published online 17 August 2005
\end{abstract}

Keywords: methamphetamine; pharmacokinetics; dopamine; locomotion; microdialysis; animal model; stereotypy

\section{INTRODUCTION}

Mounting evidence of the continued worldwide spread of methamphetamine (METH) abuse underscores the urgency of understanding the effects of long-term exposure to this drug. The growing awareness of this problem has stimulated a broad spectrum of research in both humans and experimental animals. Clinical studies, in particular those using various neuroimaging techniques, have revealed potentially persistent or even permanent METH-induced neurobiological alterations (Wilson et al, 1996; McCann et al, 1998; Ernst et al, 2000; Sekine et al, 2001; Thompson et al, 2004). Additional evidence suggests that such changes may produce cognitive impairments (Ornstein et al, 2000; Volkow et al, 2001; Simon et al, 2002; Kalechstein et al, 2003) as well as neuropsychiatric complications (eg Segal

\footnotetext{
*Correspondence: Dr DS Segal, Department of Psychiatry (0603), University of California San Diego School of Medicine, La Jolla, CA 92093, USA, Tel: + I 858534 4044, Fax: + I 8585347653 ,

E-mail: dsegal@ucsd.edu

Received 19 April 2005; revised and accepted 7 July 2005

Online publication: 7 July 2005 at http://www.acnp.org/citations/ Npp070705050254/default.pdf
}

and Schuckit, 1983; Angrist, 1994). However, despite advances in clinical research, limitations in the ability to characterize accurately the extent of METH exposure, as well as possible confounding by factors such as the use of other drugs, has stimulated the development of preclinical paradigms in which more invasive methodologies can be used to facilitate an understanding of the underlying mechanisms and processes responsible for the effects associated with long-term METH exposure.

In this context, we have argued on the basis of accumulating evidence that the translational relevance of animal treatment models is largely based on the degree to which the plasma METH profiles produced by the drug protocol approximates human exposure patterns. In this regard, a critical issue often overlooked especially in studies carried out with rodents is the marked difference in METH half-life between the two species, that is, about $1 \mathrm{~h}$ in rats (Melega et al, 1995; Hutchaleelaha and Mayersohn, 1996; Rivière et al, 1999, 2000) and 10-12 h in humans (Cook et al, 1993; Mendelson et al, 1995; Harris et al, 2003a). Importantly, the difference in METH exposure patterns between humans and rodents is even more pronounced with repeated drug administration, that is, 
the rate and magnitude of drug accumulation, as a function of interinjection interval, is significantly greater in humans because of the longer drug half-life (Cho et al, 2001). Therefore, the results of preclinical studies using traditional chronic METH regimens may not fully reveal the spectrum of effects resulting from similar drug administration paradigms in humans.

As profound differences in behavioral and neurobiological consequences can occur as a function of duration of METH exposure (Ellison et al, 1978; Ellinwood and Lee, 1983; Davidson et al, 2001; Cryan et al, 2003; Samaha et al, 2004), and because of the advantages obtained from using rodents to study underlying mechanisms, we developed a 'dynamic infusion' procedure to compensate for the more rapid elimination half-life in rats, and thus more closely simulate the human METH exposure profile in our experimental animals. In this study, we examined the behavioral and striatal extracellular dopamine (DA) effects produced by single daily dynamic infusions of METH over 15 days.

\section{MATERIALS AND METHODS}

\section{Subjects}

Male Sprague-Dawley rats weighing 275-300 g were obtained from Harlan Labs (Gilroy, CA) and were housed for at least 2 weeks prior to surgery in groups of two or three animals, in wire mesh cages, with ad libitum access to food and water. The room temperature $\left(22^{\circ} \mathrm{C}\right)$ and humidity $(55 \pm 5 \%)$ were controlled and maintained on a reversed $12-$ $\mathrm{h}$ dark (0700 to 1900 hours) and 12-h light cycle to allow for the start of treatment during the normal active phase of the rat's awake/sleeping cycle (Devoto et al, 2004). During the dark period, all facilities were illuminated with red light to facilitate observation of the animals. These studies adhered to animal welfare guidelines (National Research Council, 'Guide for the Care and Use of Laboratory Animals', 1996).

\section{Drugs}

Methamphetamine hydrochloride (Sigma Chemical Co., St Louis, MO) was dissolved in $0.9 \%$ saline containing $3.0 \mathrm{U} /$ day heparin and $3.75 \mathrm{mg} /$ day timentin and administered intravenously (i.v.) (see below). Control animals received a comparable vehicle administration.

\section{Surgery}

After 2 weeks of acclimation, animals were implanted with i.v. catheters under Halothane anesthesia. Catheters were constructed by fitting a $13 \mathrm{~cm}$ length of silastic tubing to a guide cannula, bent at a right angle. The guide cannula was embedded in dental cement and attached to a 1 inch circle of marlex mesh and mounted on the animal's back. The silastic tubing was passed subcutaneously (s.c.) from the back of the rat to the right external jugular vein. A Tygon cap was inserted over the guide cannula to maintain a closed system. For dialysis studies, animals were concurrently implanted unilaterally or bilaterally with guide cannulae using procedures previously described in detail (Kuczenski and Segal, 1989). Guide cannulae extended $2.6 \mathrm{~mm}$ below the surface of the skull and were aimed at the caudate-putamen $(1.0 \mathrm{~mm}$ anterior, $\pm 2.0 \mathrm{~mm}$ lateral $)$. Animals were singly housed after surgery, and on a daily basis between surgery and experimental testing, the catheter was flushed with sterile saline $(0.15 \mathrm{ml})$ containing 3.0 USP units heparin and $3.75 \mathrm{mg}$ timentin.

\section{Apparatus}

Behavior was monitored in custom-designed activity chambers (Segal and Kuczenski, 1987). Each of the chambers $\left(30 \times 20 \times 38 \mathrm{~cm}^{3}\right)$ was located in a soundattenuated cabinet maintained on a reversed 12 -h dark/12$\mathrm{h}$ light cycle with constant temperature $\left(22^{\circ} \mathrm{C}\right)$ and humidity $(55 \pm 5 \%)$. Movements of the animal between quadrants (ie crossovers) and rearings against the wall, as well as eating and drinking and other vertical and horizontal movements were monitored continuously by computer. In addition, the behavior in all experimental chambers was concurrently and continuously digitally recorded using micropinhole cameras equipped with wide-angle lenses and mounted on the door of each chamber. Video images were collected via GV-800 BNC Capture cards and Geovision software, and then stored on DVD media for subsequent evaluation. Representative animals were selected from each experimental group to reflect the full range and pattern of locomotor activation associated with the drug response; subsequently, raters who were unaware of the specific experimental conditions rated the recordings on the basis of behavior ethograms and rating procedures established previously (Segal and Kuczenski, 1987). Specific behaviors were rated as the percentage of the observation interval during which the animal displayed that behavior. The appearance of any novel behavior patterns, undetectable by our automated methods, was also noted by the rater. In the present study, animals were rated during 2-min observation intervals every $15 \mathrm{~min}$ during the initial hour (1000-1100), every 30 min during the next $2 \mathrm{~h}$ (1100-1300), and hourly during the next $13 \mathrm{~h}$ (1400-0200). During the 0300-0700 period, animals were generally sleeping, and therefore were continuously scanned to characterize behaviors that interrupted the sleep pattern (see Results).

\section{General Procedures}

About 2 weeks after surgery, animals were placed in individual experimental chambers, connected to the syringe tubing, and remained in the chambers for the duration of the experiment. Each morning throughout the study, at the beginning of the dark phase (0700 hours), the behavioral chambers were serviced and the animals were weighed. Following a 3-day acclimation period, during which animals received daily dynamic infusions of saline (see below), drug administration was initiated.

\section{Drug Administration}

Remote drug delivery was accomplished with Med Associates Inc. PHM-100 syringe pumps. Tubing from the syringe pump was attached to the catheter via a liquid swivel and a commercially available cannula connector (Plastic Products). Drug or saline administration was initiated at 1000 hours according to the following pattern: drug delivery 
involved an initial i.v. infusion of $\mathrm{METH}(0.5 \mathrm{mg} / \mathrm{kg}$, administered in $0.105 \mathrm{ml}$ ) over a 6-s interval. The 6-s interval was chosen on the basis of recent studies suggesting that many i.v. METH abusers typically inject drug over a range of $5-10 \mathrm{~s}$ (Samaha et al, 2004) (R Rawson, UCLA Department of Psychiatry, personal communication). An $80 \mathrm{~dB}, 2.2 \mathrm{kHz}$ tone-cue was presented to each animal for $5 \mathrm{~s}$ prior to, and during the 6-s drug injection. The audible tone was used to provide rats with a drug-predictive cue, shown in recent studies to be a potentially significant factor in stimulant-induced neuronal alterations (Ghitza et al, 2003). As rat plasma METH concentrations decline much more rapidly than in humans, additional METH administration was required to simulate human METH pharmacokinetics. To accomplish this, subsequent to the initial infusion, METH was delivered according to a computer-controlled program in the form of short-duration injections or minipulses (each $0.28 \mu \mathrm{l}(1.3 \mu \mathrm{g} / \mathrm{kg}$ for a $0.5 \mathrm{mg} / \mathrm{kg}$ initial dose) over a 16-ms duration), in order to impose a plasma profile with a 12-h half-life for the drug. The amount of METH delivered following the initial infusion was calculated according to the following formulation in which the desired plasma concentration is defined by the simple one-compartment open model relationship

$$
g(t)=C_{0} \exp \left(-k_{\mathrm{h}} \times t\right)
$$

where $C_{0}$ is the plasma METH concentration achieved in response to the initial infusion and $k_{\mathrm{h}}$ is the elimination rate constant for a 12 -h half-life $\left(0.05775 \mathrm{~h}^{-1}\right)$. The desired rate of change of plasma METH concentration as a function of time was defined as

$$
\mathrm{d} g(t) / \mathrm{d} t=k_{\mathrm{r}} \times g(t)+f(t)
$$

where $k_{\mathrm{r}}$ is the elimination rate constant for a 1-h half-life in the rat $\left(0.693 \mathrm{~h}^{-1}\right)$ and $f(t)$ is the amount of drug to be added per unit time, as a function of time, in order to achieve the desired plasma METH concentrations. Note that, if $f(t)$ is zero, a situation which would correspond to normal rat physiological METH pharmacokinetics, then the solution to this differential equation would be (3):

$$
g(t)=C_{0} \exp \left(-k_{\mathrm{r}} \times t\right)
$$

Combining Equations (1) and (2) to solve $f(t)$ yields

$$
f(t)=C_{0}\left(-k_{\mathrm{h}}+k_{\mathrm{r}}\right) \exp \left(-k_{\mathrm{h}} \times t\right)
$$

The temporal profile of minipulses administered after the initial 6-s drug injection is summarized in Figure 1. For the $0.5 \mathrm{mg} / \mathrm{kg}$ dose, each minipulse delivered $1.3 \mu \mathrm{g} / \mathrm{kg} \mathrm{METH}$, and each animal received a cumulative dose of $4.61 \mathrm{mg} / \mathrm{kg}$ over a 24 -h interval to achieve $24 \mathrm{~h}$ of drug exposure in a temporal pattern that is similar to human METH pharmacokinetics.

In an initial characterization of this methodology, we used anesthetized animals prepared with an indwelling jugular catheter for drug delivery and a microdialysis probe in the caudate-putamen to assess extracellular DA. We found that about 20 minipulses, delivering $5.6 \mu \mathrm{l}$, or $26 \mu \mathrm{g} /$ $\mathrm{kg}$ METH was required to produce a measurable effect on extracellular DA, consistent with the assumption that gradual changes in plasma drug concentration occur with this procedure.

\section{Single Daily Dynamic Infusion Treatment Protocol}

Following acclimation to the behavioral chambers, animals received single daily dynamic infusions of $0.5 \mathrm{mg} / \mathrm{kg} \mathrm{METH}$

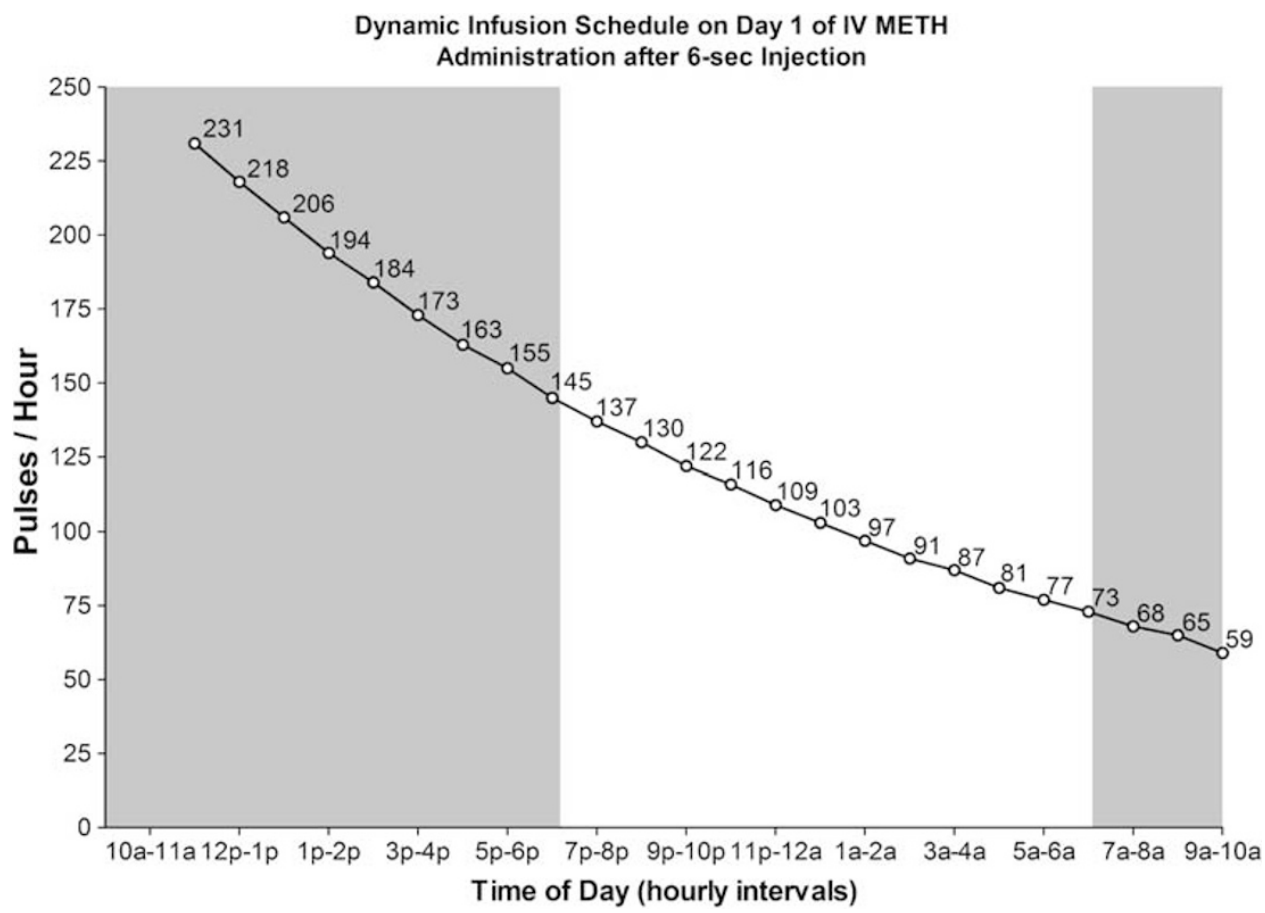

Figure I Temporal pattern of minipulses over a 24-h period during the first dynamic infusion of METH. Following a 6-s injection of drug at I000 hours, METH was delivered according to a computer-controlled program in the form of short-duration injections or minipulses (each $0.28 \mu \mathrm{l}$ over a $16 \mathrm{~ms}$ duration delivering $1.3 \mu \mathrm{g} / \mathrm{kg}$ for a $0.5 \mathrm{mg} / \mathrm{kg}$ initial dose) as described in Materials and methods. The values on the curve represent the number of pulses administered during the previous hour in order to achieve a 12-h half-life. Shading represents the dark/active phase of the light-dark cycle. 
$(n=30)$ or comparable volumes of saline $(n=10)$ for 15 consecutive days. Based on a plasma METH half-life of $12 \mathrm{~h}$, single daily infusions of the drug result in substantial METH accumulation, and residual preinjection levels of the drug on the following day progressively increase until a plateau is reached after about 5-6 half-lives (Figure 2). As a consequence, as with humans using METH once a day, rats receiving dynamic infusions would be exposed to continuous, fluctuating levels of the drug, with the highest peak plasma METH concentration occurring after about the fourth injection. Values for estimated daily peak plasma concentrations, residual drug levels at the time of the next day's infusion, and total daily dose of METH are summarized for representative days in Table 1. Some investigators (eg Schmidt et al, 1985; Gygi et al, 1996), using relatively high doses of METH (eg acute 'binge' patterns of administration), have reported subsequent changes in METH pharmacokinetics. However, we have not observed altered pharmacokinetics using repeated administration of more moderate doses (eg (Segal and Kuczenski, 1997b; O'Neil et al, unpublished). Furthermore, most evidence suggests that repeated administration of METH in humans is not associated with changes in drug disposition or metabolism (Anggard et al, 1973; PerezReyes et al, 1991; Cook et al, 1992). Therefore, for the present studies, we followed a drug treatment regimen assuming that METH pharmacokinetics remained unaltered over the course of drug exposure.

On the day following the 15th daily dynamic infusion, 10 animals in the experimental group continued to receive METH for an additional $24 \mathrm{~h}$ in order to simulate the gradual decline in plasma drug levels that would be anticipated for a half-life of $12 \mathrm{~h}$. On days 17-19, these animals received dynamic infusions of saline, followed on Days 20-22, with single daily dynamic infusions of $0.5 \mathrm{mg} / \mathrm{kg} \mathrm{METH}$.

There was no obvious evidence of METH-induced toxicity throughout the experiment; however, between Days 8 and 10, three METH-treated rats exhibiting blood on their

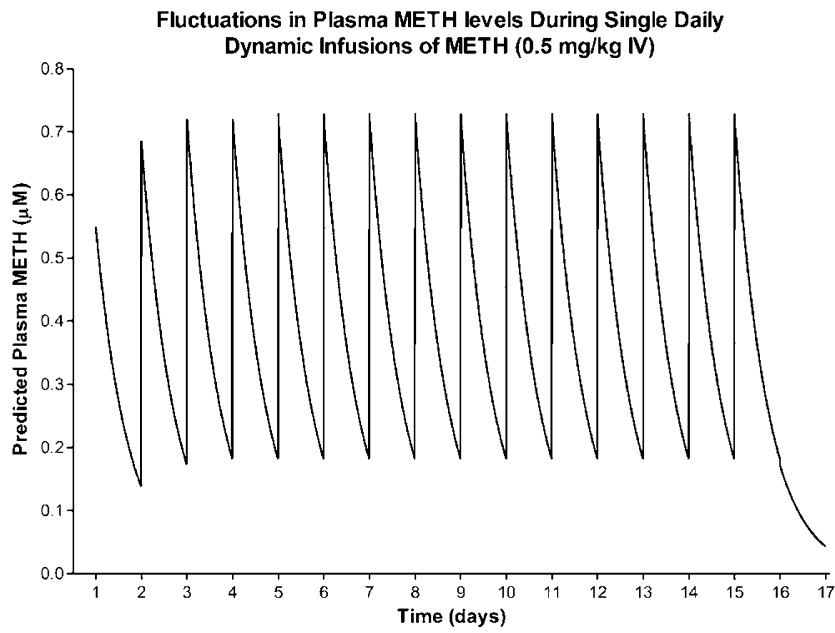

Figure 2 Predicted plasma METH concentrations with single daily dynamic infusion of $0.5 \mathrm{mg} / \mathrm{kg}$ METH for 15 days. Predicted values are based on an initial peak plasma METH concentration derived from experimental plasma METH levels depicted in Figure 3.
Table I Drug Concentrations and Doses on Representative Days during Single Daily METH Dynamic Infusion

\begin{tabular}{lccccc}
\hline & Day I & Day 2 & Day 5 & Day 10 & Day I5 \\
\hline $\begin{array}{l}\text { Peak plasma METH } \\
(\mu \mathrm{M})\end{array}$ & 0.55 & 0.69 & 0.73 & 0.73 & 0.73 \\
$\begin{array}{l}\text { Residual METH prior } \\
\text { to next infusion }(\mu \mathrm{M})\end{array}$ & 0.14 & 0.18 & 0.18 & 0.18 \\
$\begin{array}{l}\text { Total 24h dose }(\mathrm{mg} / \\
\mathrm{kg})\end{array}$ & 4.63 & 5.66 & 6.00 & 6.00 & 6.00 \\
\hline
\end{tabular}

Plasma METH concentrations were calculated assuming a simple onecompartment open model and a METH half-life of $12 \mathrm{~h}$. Peak plasma

concentration (Day I) is based on actual values following dynamic infusion of $0.5 \mathrm{mg} / \mathrm{kg}$ METH (Figure 3). Values for total $24 \mathrm{~h}$ dose reflect actual administered drug.

forepaws produced by prolonged intense licking behaviors were removed from the study. Data for these animals were not included in the analyses. Experimental animals lost on average about $12 \%$ of their initial body weights during the first 5 days of drug exposure, at which time weights stabilized, and, in fact, by Day 15, significant weight recovery from Day 5 weights had occurred $(18 \pm 4 \mathrm{~g}$, $p<0.001)$. Although these weight losses were relatively small, dose adjustments based on treatment group weight changes were incorporated on Days 4, 11, and 18 of the treatment regimen.

\section{Microdialysis}

In order to characterize the effects of multiple daily METH infusions on the extracellular DA response, a separate group of animals $(n=10)$, implanted with bilateral guide cannulae, were concurrently treated with the identical single daily dynamic infusion protocol. About $6 \mathrm{~h}$ prior to the first drug administration, these animals were lightly anesthetized with Halothane, microdialysis probes were inserted into one guide cannula, and dialysis samples were collected during the first METH dynamic infusion. On the morning of the 15th day of METH treatment, dialysis probes were similarly inserted into the guide cannula contralateral to the first dialysis site, and samples were collected during the METH dynamic infusion.

A separate microdialysis study was performed to determine whether the temporal profile of the apparent extracellular DA response varied as a function of the relatively short interval between probe insertion and drug administration $(6 \mathrm{~h})$. In this study, we followed our traditional procedure: on the day prior to the experimental day (1500-1600 hours), each rat was lightly anesthetized with Halothane, placed in the dialysis chamber, and the dialysis probe was inserted to allow about $18 \mathrm{~h}$ equilibration prior to experimental manipulation. The results of this study revealed no quantitative or qualitative differences in the response profiles for caudate DA compared to the Day 1 dialysis described above, and therefore the data from these two separate groups of animals were combined and are presented in Figure 3.

Concentric microdialysis probes were constructed of Spectra/Por hollow fiber (MW cutoff 6000, o.d. 250 $\mu$ ) 
according to the method of Robinson and Whishaw (1988) with modifications (Kuczenski and Segal, 1989). The length of the active probe membrane was $3 \mathrm{~mm}$. Probes were perfused with artificial cerebrospinal fluid $(147 \mathrm{mM} \mathrm{NaCl}$, $1.2 \mathrm{mM} \mathrm{CaCl}_{2}, 0.9 \mathrm{mM} \mathrm{MgCl}_{2}, 4.0 \mathrm{mM} \mathrm{KCl}$ ) delivered by a microinfusion pump $(1.5 \mu \mathrm{l} / \mathrm{min})$ via $50 \mathrm{~cm}$ of microline ethyl vinyl acetate tubing connected to a fluid swivel. Dialysate was collected through glass capillary tubing into vials containing $20 \mu \mathrm{l}$ of $25 \%$ methanol, $0.2 \mathrm{M}$ sodium citrate, $\mathrm{pH}$ 3.8. Under these conditions, dialysate DA and metabolites were stable throughout the collection and analysis interval. Samples were collected outside the experimental chamber to avoid disturbing the animal. Individual probe recoveries were estimated by sampling a standard DA solution in vitro. At the end of the experiment, each animal was perfused with formalin for histological verification of probe placements.

Dialysate samples were collected at $30-60 \mathrm{~min}$ intervals, with the exception of the overnight samples. Samples were assayed for DA, 3,4-dihydroxyphenylacetic acid (DOPAC), homovanillic acid (HVA), and 3-methoxytyramine. The HPLC-EC consisted of a $100 \mathrm{~mm} \times 4.6 \mathrm{~mm}$ ODS-C18 $3 \mu$ column (Regis) maintained at $40^{\circ}$. Mobile phase $(0.05 \mathrm{M}$ citric acid, $7 \%$ methanol, $0.1 \mathrm{mM} \mathrm{Na} \mathrm{NaDTA}_{2}$, and $0.2 \mathrm{mM}$ octane sulfonate adjusted to $\mathrm{pH} 4.0-4.5)$ was delivered at $0.6-0.8 \mathrm{ml} / \mathrm{min}$ by a Waters model $510 \mathrm{pump}$. Amines were detected with a Waters 460 detector with a glassy carbon electrode maintained at $+0.65 \mathrm{~V}$ relative to a Ag/AgCl reference electrode. Concentrations were estimated from peak heights using a Waters Maxima 820 data station. Substances in the dialysates were corrected for individual probe recoveries to account for this source of variability, and, although the exact relationship between dialysate concentration and actual extracellular transmitter content is not clear, values are presented as dialysate concentration to allow for meaningful comparisons to other data in the literature.

\section{Plasma METH and Amphetamine (AMPH)}

For pharmacokinetic analyses, separate groups of animals ( $n$ 's $=3-6$ per time point) were killed by decapitation at various times after initiation of drug infusion, and trunk blood was collected in EDTA tubes. Plasma was isolated and immediately frozen on dry ice. The concentrations of METH and AMPH were determined by NMS Laboratories, Willow Grove, PA.

\section{Data Analysis}

Behavioral and neurochemical data were statistically analyzed using repeated measures ANOVA and $t$-tests with Bonferroni corrections for specific group/time comparisons. As the response to saline infusion did not exhibit significant changes across days, an average saline response was included in all figures for ease and clarity of presentation.

\section{RESULTS}

\section{Plasma METH Concentrations}

During the first day of treatment, plasma METH concentrations were determined from the trunk blood of rats at various times after the initiation of the dynamic infusion procedure (Figure 3 ). In contrast to the rapid decline in METH levels associated with the relatively short half-life for

\section{Extracellular Dopamine and Plasma METH and AMPH in Response to a Dynamic Infusion of METH $(0.5 \mathrm{mg} / \mathrm{kg}$, IV)}

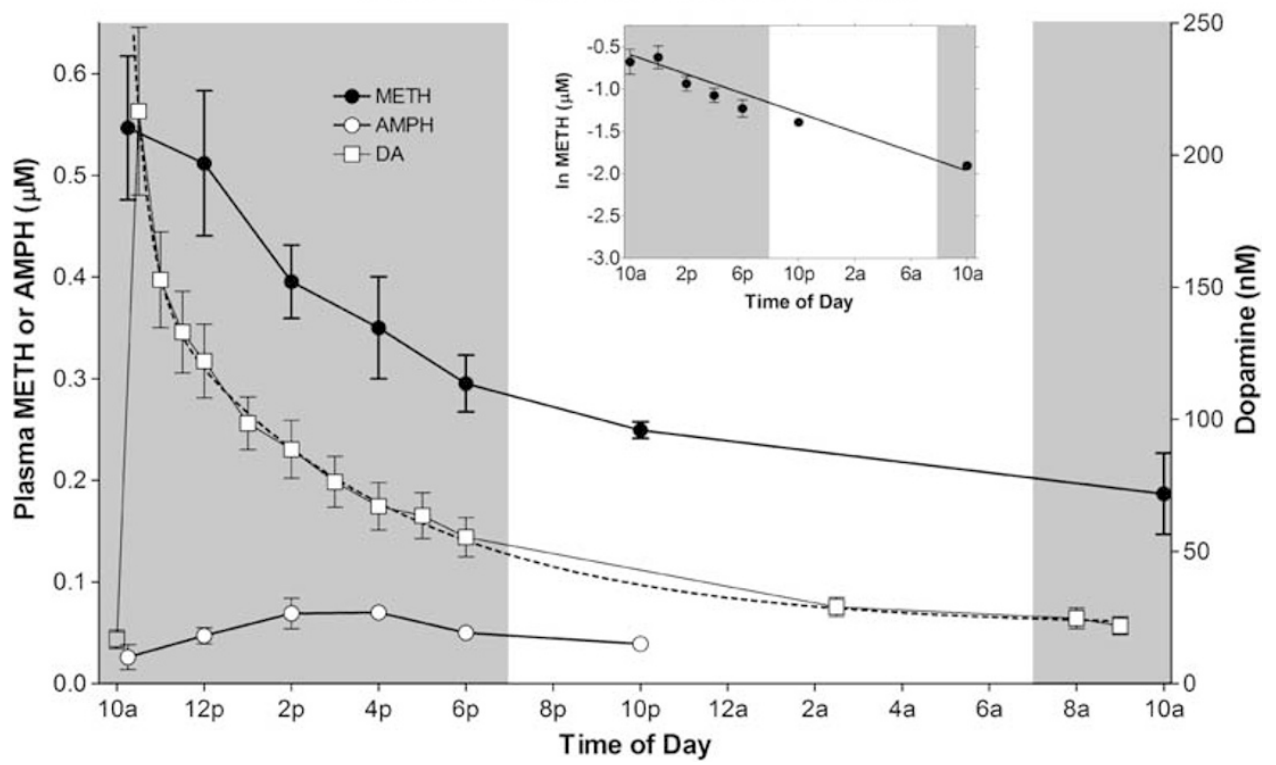

Figure 3 Temporal profile of the plasma concentration of METH and AMPH, and of caudate extracellular DA during dynamic infusion of METH ( 0.5 mg/ $\mathrm{kg}$ ). For METH and AMPH, plasma was collected from separate groups of animals (n's = 3-6) at various times after the start of drug administration. Values are presented as means \pm SEM. Inset: Semilogarithmic plot of plasma concentration of METH during dynamic infusion of METH. The line represents the results of a linear regression with a slope of $-0.599 \pm 0.0069 \mathrm{~h}^{-1}$, reflecting a half-life for METH of $11.6 \pm 1.3 \mathrm{~h}$. For caudate extracellular DA, values represent the mean dialysate concentration \pm SEM from separate experiments $(n ' s=14$ ). The dashed line depicts the results of a nonlinear regression analysis for extracellular DA. $Y=305 \mathrm{e}^{(-0.051 \mathrm{t})}+143 \mathrm{e}^{(-0.003 \mathrm{t})}$. Shading represents the dark/active phase of the light-dark cycle. 
the drug in the rat, dynamic infusion of the $0.5 \mathrm{mg} / \mathrm{kg}$ dose resulted in a much more gradual decline in plasma drug concentration. The METH level at the earliest time point tested (15 min following initiation of drug administration) was $0.54 \pm 0.07 \mu \mathrm{M}$, similar to the level that is found in humans receiving a comparable dose of the drug (Cook et al, 1993; Harris et al, 2003a, b). Over the next $24 \mathrm{~h}$, METH levels gradually declined with a half-life of $11.6 \pm 1.3 \mathrm{~h}$ (inset, Figure 3 ). The consequent prolonged exposure resulted in an $\mathrm{AUC}_{0 \rightarrow \infty}$ of $9.4 \mu \mathrm{Mh}$, about 20 -fold larger than typical rat pharmacokinetics $(0.45 \mu \mathrm{Mh}$ (Rivière et al, 1999). In contrast to the temporal profile for METH, its primary active metabolite, AMPH, gradually increased from $0.03 \pm 0.01 \mu \mathrm{M}$ at the $15 \mathrm{~min}$ time point, to a maximum of $0.08 \pm 0.03 \mu \mathrm{M}$ at $4 \mathrm{~h}$ (Figure 3). This concentration remained relatively unchanged until at least $12 \mathrm{~h}$ after the start of drug administration, but was below the limits of quantitation by $24 \mathrm{~h}$. Thus, it does not appear that AMPH levels substantially contributed to the overall stimulant effects during the first dynamic infusion.

\section{Striatal DA Response: Acute METH Administration}

Extracellular DA in dorsal striatum rapidly increased in response to dynamic infusion of $\mathrm{METH}$, achieving peak levels $(217 \pm 32 \mathrm{nM} ; \sim 1300 \%$ of baseline levels) during the initial 30-min sampling interval (Figure 3). A nonlinear regression revealed that the temporal pattern of DA concentrations exhibited a biphasic decline, beginning with a relatively rapid fall to about one-half peak levels within the first $2 \mathrm{~h}$, followed by a more gradual decline with a halflife of $3.7 \mathrm{~h}$ over the remainder of the 24 -h drug infusion period. The increase in extracellular DA was detectable for at least $12 \mathrm{~h}$ (until about 2200 hours), at which time DA remained elevated at $192 \pm 26 \%$ of baseline. By the 22 -h time point (0800 hours), extracellular DA was no longer significantly different from baseline values. The DA metabolites, DOPAC and HVA, exhibited a rapid decline during the initial hour following drug administration (baseline and 1-h time point; DOPAC (nM): $5817 \pm 349$ and $3159 \pm 262$; HVA (nM): $3419 \pm 327$ and $2014 \pm 205$; $p<0.001$ for each metabolite), and remained at these levels for at least $12 \mathrm{~h}$ before returning toward baseline values during the overnight collection interval. By the 22-h time point (0800 hours), neither DOPAC nor HVA levels were significantly different from predrug values (22-h time point as percent of baseline: DOPAC, $103.8 \pm 18.7$; HVA, $104.8 \pm 14.4$ ).

These results indicated that METH no longer increased extracellular DA by about $12-22 \mathrm{~h}$ after the initiation of METH infusion in spite of the continued presence of plasma METH levels near $0.16-0.2 \mu \mathrm{M}$. Although it was possible that this concentration of METH was too low to affect caudate DA release, the results of previous pharmacokinetic/pharmacodynamic comparisons suggested that this plasma level of stimulant produced by acute injection is associated with a significant increase in striatal extracellular DA (Melega et al, 1995; Kuczenski et al, 1997a; Cho et al, 1999). Alternatively, accumulating evidence now suggests that with prolonged exposure, acute tolerance (ie tachyphylaxis) develops to many stimulant behavioral and physiological effects (Angrist et al, 1987; Angrist, 1987;
Cook et al, 1993; Swanson et al, 2002; Greenhill et al, 2003; Foltin and Haney, 2004). Therefore, to identify a possible explanation for the apparent temporal dissociation between the plasma METH and striatal DA response profiles, in a separate group of animals we administered a dose of METH $(0.15 \mathrm{mg} / \mathrm{kg})$ which, based on our earlier pharmacokinetic results (Figure 3), we estimated would produce a peak plasma concentration of about $0.16 \mu \mathrm{M}(25-30 \%$ of the peak plasma concentration associated with the $0.5 \mathrm{mg} / \mathrm{kg}$ METH dose). Consistent with this estimate, we found that dynamic infusion of $0.15 \mathrm{mg} / \mathrm{kg}$ produced a peak DA response of about $30 \%$ of the $0.5 \mathrm{mg} / \mathrm{kg}$ dose (peak DA responses: $0.15 \mathrm{mg} / \mathrm{kg} \quad \mathrm{METH}, \quad 65.3 \pm 21 \mathrm{nM} ; \quad 0.5 \mathrm{mg} / \mathrm{kg}$ METH, $217 \pm 32 \mathrm{nM}$ ). For this relatively low METH dose, extracellular DA remained significantly elevated for about $2 \mathrm{~h}$ following the start of dynamic infusion before returning to baseline levels.

\section{Behavior: Locomotor Activation}

On Day 1, locomotion, that is, crossovers (Figure 4a and b), rapidly increased after the start of drug administration and was significantly elevated within the first $5 \mathrm{~min}(0-5 \mathrm{~min}$ : SALINE, $0.3 \pm 0.3 ; \quad$ METH, $11.7 \pm 1.9, \quad p<0.001)$. Peak activity was achieved within the first hour, and remained at about this level for between 2 and $4 \mathrm{~h}$ before gradually declining over the next $12-14 \mathrm{~h}$. Crossovers were no longer significantly different from control values by about 0200 hours, that is, $16-18 \mathrm{~h}$ after the beginning of METH infusion. With repeated administration, the onset of activation (0$15 \mathrm{~min}$ ) was similar on all days (Figure 4c); however, examination of the full temporal pattern of locomotor activity revealed a marked change in this behavior across days: a progressive decline in both the magnitude (Figure $4 \mathrm{a}$ and b) and duration (Figure $4 \mathrm{a}$ and d) of the response. The decreased duration in the locomotor response was particularly marked: locomotion was elevated until about 0200 hours on Day 1 but only until about 1900 hours on Day 15 (16 and $10 \mathrm{~h}$, respectively, after the initiation of treatment on each day).

Like crossovers, rearings exhibited a significant increase within the first $15 \mathrm{~min}$ of drug administration (data not shown), although even during this early interval, the magnitude of this elevation was progressively lower as a function of treatment day $(\mathrm{F}=34.7, p=0.001)$. Furthermore, this behavior did not represent a significant component of the total METH-induced behavioral activation profile (see below for further description).

\section{Behavior: Observational Ratings}

Characterization of the qualitative features of the behavior provided a critical dimension necessary to fully identify the response changes that occurred across successive treatment days. In this regard, observational rating revealed that the progressive decline in locomotion, particularly during the initial $3 \mathrm{~h}$ of dynamic infusion for each day (1000-1300 hours), corresponded to the emergence of gradually more prolonged episodes of focused stereotypy (Figure $5 a$ and $b$ ). Furthermore, during this early period, the form of stereotypy progressed from predominately focused sniffing during the first treatment day to an admixture of oral 
Single Daily Dynamic Infusions of METH $(0.5 \mathrm{mg} / \mathrm{kg} \mathrm{IV})$ :

Temporal Pattern of Locomotion Across Days
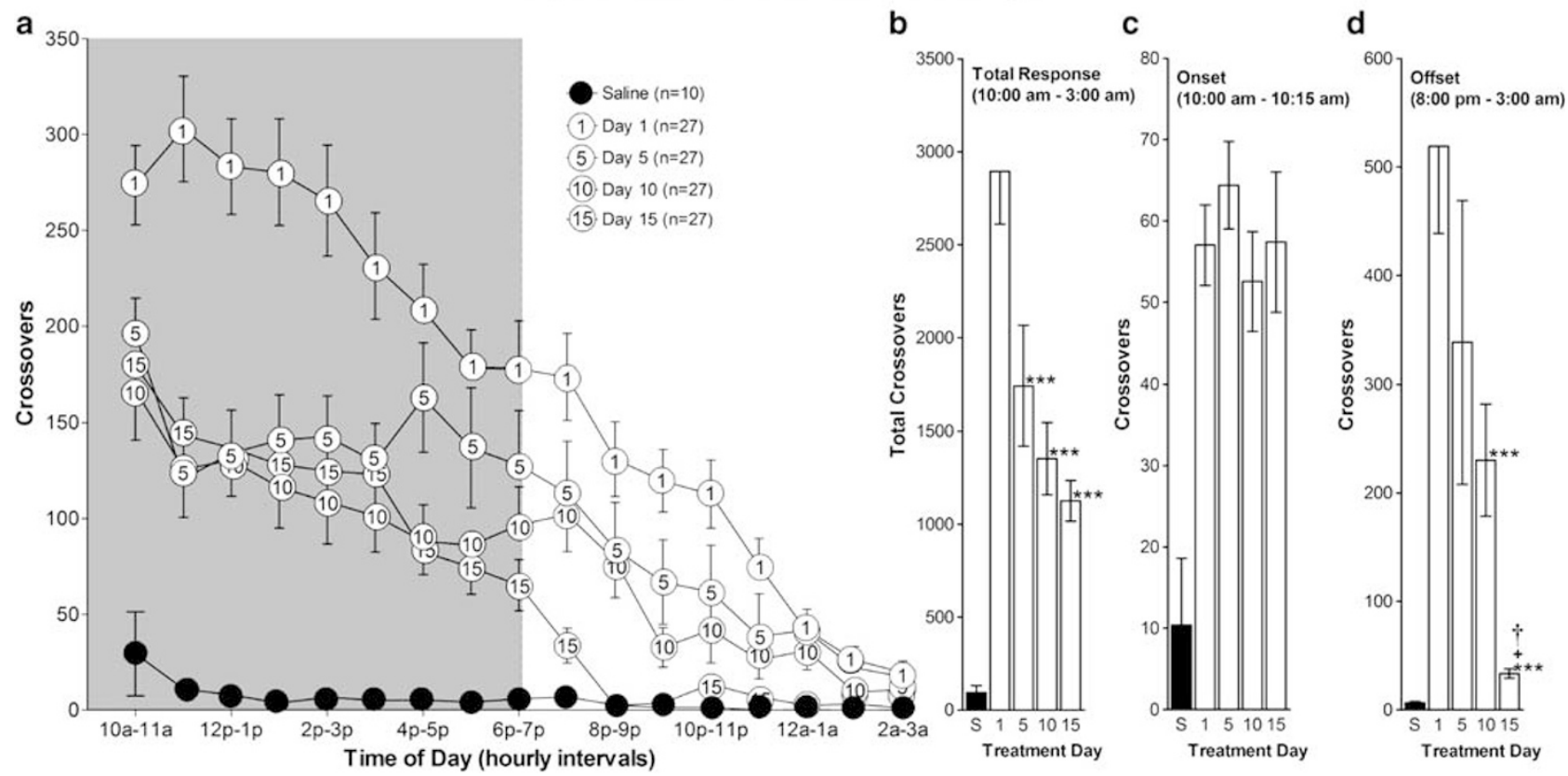

Figure 4 (a) Locomotor response on representative days to single daily dynamic infusion of METH ( $0.5 \mathrm{mg} / \mathrm{kg}$ ) (open circles) or an equivalent dynamic infusion of saline (closed circles). Numbers in parentheses indicate the number of animals in each group. Values are presented as mean crossovers \pm SEM. The number within the open circle indicates the treatment day. Shading represents the dark/active phase of the light-dark cycle. (b-d) Histograms represent cumulated crossovers during the indicated interval for representative days. In this and all subsequent figures, behavioral responses of the METH-treated groups were significantly different compared to the saline group, and for purposes of clarity are not included in the statistical comparisons. $* * * *<0.001$ compared to Day I; ${ }^{+} p<0.05$ compared to Day 5; and ${ }^{\dagger} p<0.05$ compared to Day 10.

stereotypy and focused sniffing by Day 5, followed by mostly intense oral stereotypy (object directed licking or biting) on subsequent days. As the duration and intensity of the stereotypy episodes increased, locomotion occurred primarily in the form of brief, often perseverative bursts of activity. Since downward-oriented behavior predominated, rearings were relatively rare for most animals (data not shown).

Oral behavior during the earliest observation interval (15 min after the start of dynamic infusion) increased significantly as a function of treatment day $\left(\mathrm{F}_{3,9}=5.0\right.$, $p \leqslant 0.01$ ), and this behavior peaked by about Day 10 (Figure $5 b$ and c). However, after Day 10, there was a progressive decline in the appearance of this behavior, most apparent during the later phases of the response (Figure 5c). Importantly, the decline in oral stereotypy did not correspond to the emergence of 'milder' forms of stereotypy (focused sniffing or repetitive head movements). On Day 15, the animals were continuously monitored for at least several hours in order to more accurately identify the nature of the behavior displayed after oral stereotypy ended. These observations indicated that oral stereotypy was discontinued between 1400-1900 hours, with a mean of 1513 hours $\pm 33 \mathrm{~min}$; the animals then appeared to be asleep (head down, eyes closed) within about $1 \mathrm{~h}$ afterward (at about 1556 hours $\pm 28 \mathrm{~min}$ ). During this transitional phase, the most common behaviors exhibited were general exploratory activity and grooming; on Day 15, no animal was observed to engage in any form of stereotypy after 1700 hours.

\section{Striatal Extracellular DA: Repeated METH Administration}

The extracellular DA response profiles to dynamic infusion of METH on Day 1 and Day 15 are compared in Figure 6. Baseline DA levels prior to the start of the Day 15 dynamic infusion were significantly elevated as compared to the baseline on Day $1(40.7 \pm 4.5$ vs $15.5 \pm 10.0 \mathrm{nM}$, respectively; $p<0.05)$. Comparison of the extracellular DA response profiles revealed that the peak DA concentrations were comparable on the two days. However, extracellular DA concentrations declined more slowly on Day 15; as a consequence, beginning at about $3 \mathrm{~h}$ after the start of dynamic infusion (1300 hours), DA concentrations on Day 15 were significantly higher than on Day $1(167.5 \pm 21.1 v s$ $76.8 \pm 17.5 \mathrm{nM}$, respectively; $p<0.01$ ). Day 15 DA concentrations remained significantly higher through the remainder of the response.

\section{Post-Treatment Behavior: Response to METH Challenge}

On Day 20 , the dynamic infusion of METH $(0.5 \mathrm{mg} / \mathrm{kg})$ was resumed in previously treated animals. The crossover response resulting from this treatment was not significantly different from the temporal pattern produced in the same animals during drug administration on Day 1 (Figure 7a and b); that is, both the magnitude and duration of METHinduced locomotor activation appeared to recover by 4 days following discontinuation of pretreatment. By contrast, observational rating showed that on the first challenge day, 
a

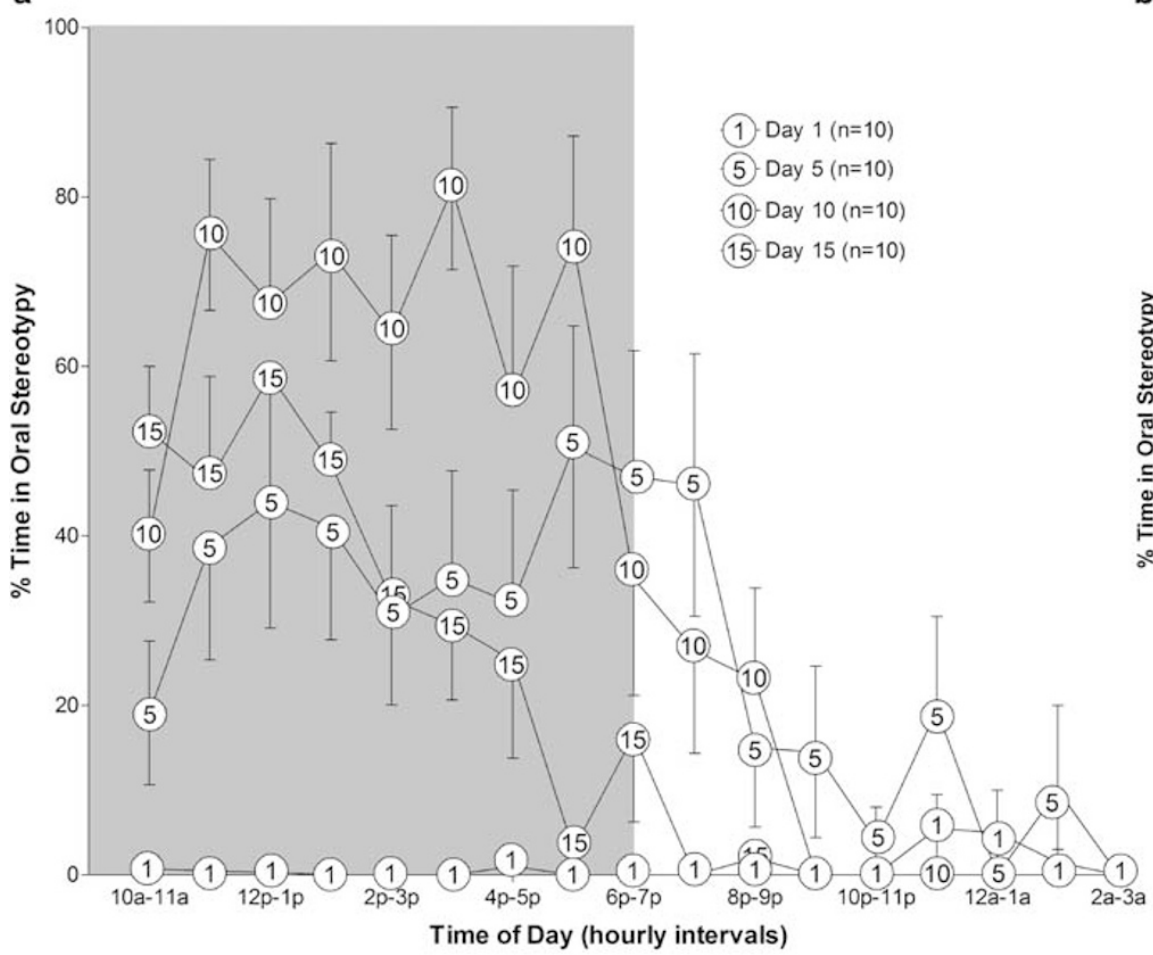

b

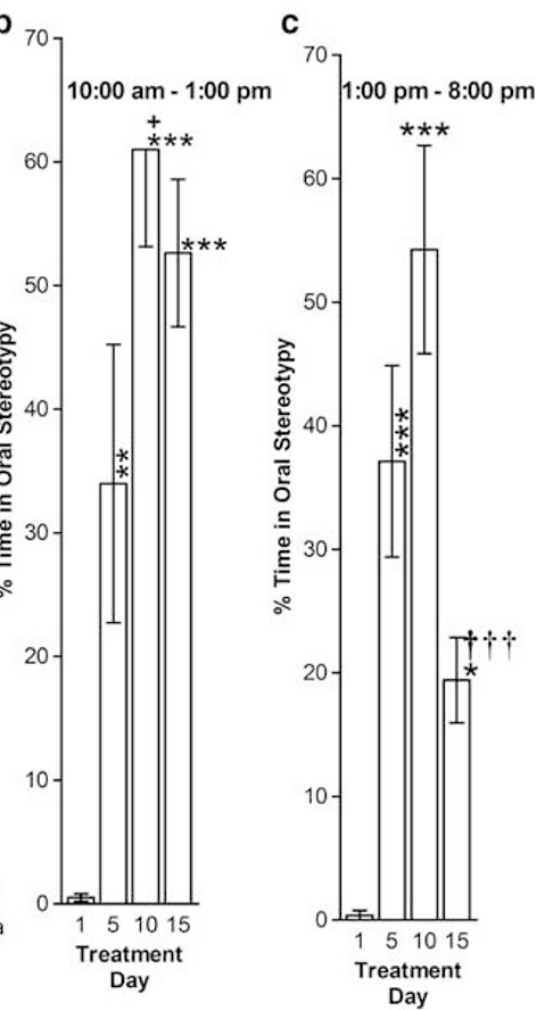

Figure 5 (a) Oral stereotypy response on representative days to single daily dynamic infusion of METH $(0.5 \mathrm{mg} / \mathrm{kg})$. Numbers in parentheses indicate the number of animals in each group. Each value represents the percent of time of the indicated interval during which the animal exhibited oral stereotypy, and is presented as means $\pm S E M$. The number within each open circle indicates the treatment day. Shading corresponds to the dark/active phase of the light-dark cycle. (b and c) Histograms depict cumulated stereotypy over the indicated interval. ${ }^{*} p<0.05,{ }^{* *} p<0.0$ I, $* * * * 0.00$ I compared to Day I; ${ }^{+} p<0.05$ compared to Day 5; and ${ }^{\dagger \dagger} p<0.001$ compared to Day 10.

these animals were engaged in significantly more intense stereotypies than on Day 1 (Figure 8), particularly during the later phases of the response (Figure 8a and c); in fact, during this 1500-2300 hours time period, the amount of oral stereotypy on Day 20 exceeded the level exhibited on Day 15. Observations also revealed that the locomotor activity throughout most of the Day 20 challenge response occurred primarily in the form of episodic bursts of rapid movements, that is, qualitatively more similar to the locomotion on Day 15 rather than on Day 1. Furthermore, after two additional METH treatment days (ie by Day 22), observations revealed no distinguishable differences in any qualitative feature of the response, and stereotypy ended in all animals by about 1900 hours In addition, the temporal pattern and total level of locomotion (about $30 \%$ of the locomotor activity displayed on Days 1 or 20) were no longer significantly different from the pattern of behavioral activation on Day 15 (Figure 7a and b).

\section{DISCUSSION}

The repeated single daily dynamic infusion procedure used in the present series of studies was designed to simulate in rats the profile of prolonged METH exposure, including the fluctuations in plasma drug concentrations, and incremental drug accumulation associated with successive i.v. injections in humans. Based on evidence that such drug exposure characteristics have important behavioral and neurobiological implications, a closer approximation of human METH exposure patterns should provide greater insight into the effects of similar treatment in drug users.

\section{Pharmacokinetics}

The dynamic infusion methodology produced a temporal pattern of plasma METH concentrations, which simulated the human profile in several important respects. First, the apparent half-life achieved $(11.6 \pm 1.3 \mathrm{~h})$ was well within the range reported for a variety of i.v. METH doses in human volunteers (11.4-12.2 h) (Cook et al, 1993; Mendelson et al, 1995; Harris et al, 2003a). Second, the plasma METH concentration at the earliest time assessed after the start of METH infusion $(0.54 \mu \mathrm{M}$ at $15 \mathrm{~min}$ for the $0.5 \mathrm{mg} / \mathrm{kg}$ dose $)$ was similar, although about $80 \%$ of the value expected from extrapolation, to a comparable dose in humans $(0.6-0.7 \mu \mathrm{M})$ (Cook et al, 1993; Harris et al, 2003a,b). Third, the area under the plasma concentration $v s$ time curve $(9.4 \mu \mathrm{Mh})$ was 20 -fold higher than following typical rat pharmacoki- 
Dopamine Response to Single Daily Dynamic Infusions of METH $(0.5 \mathrm{mg} / \mathrm{kg} \mathrm{IV})$ : Day 1 vs Day 15

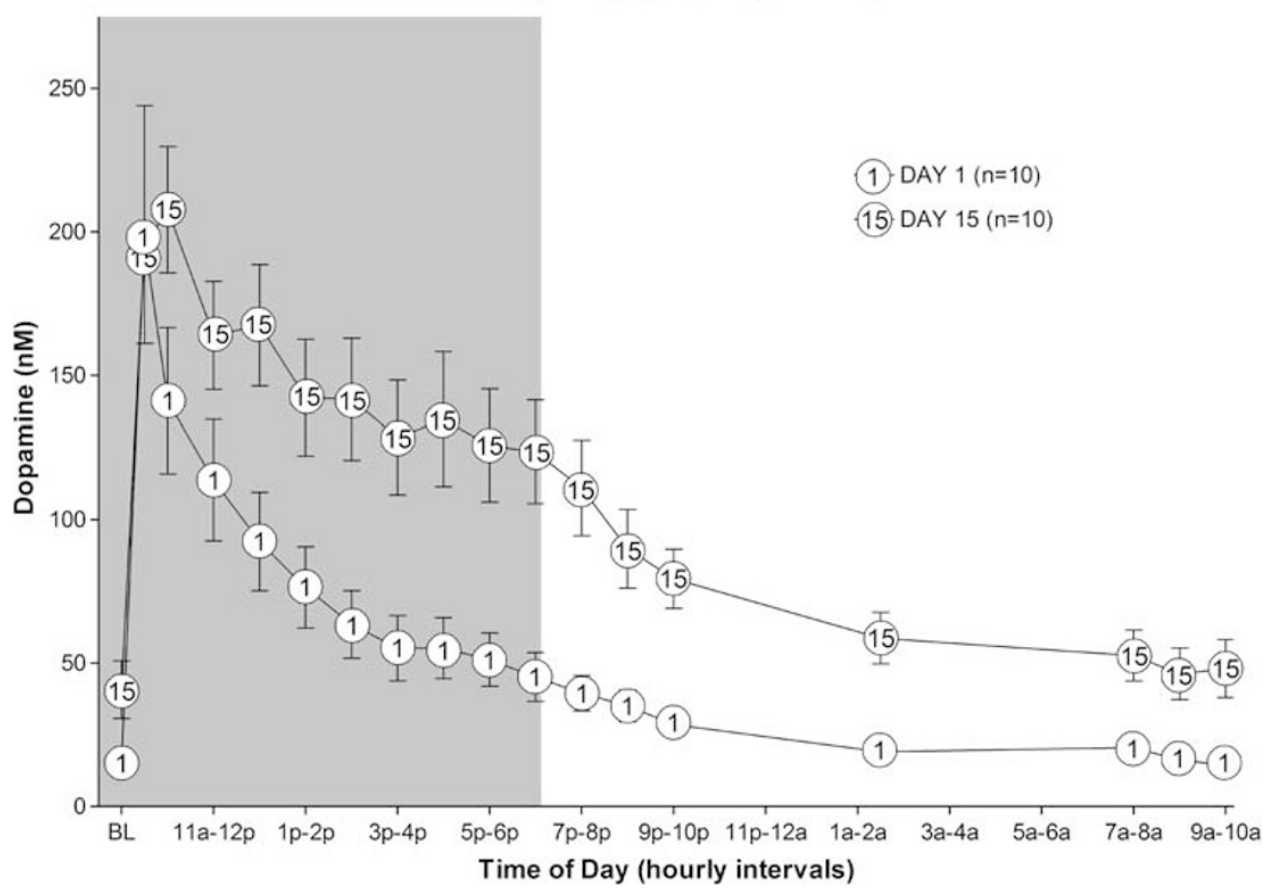

Figure 6 Temporal profile of the caudate extracellular DA response to dynamic infusion of $0.5 \mathrm{mg} / \mathrm{kg}$ METH on the Ist (Day I) and I5th (Day I5) day of the single daily treatment regimen. Numbers in parentheses indicate the number of animals in the group. Values represent the means \pm SEM. The number within each open circle indicates the treatment day. BL = predrug baseline DA concentration. Shading corresponds to the dark/active phase of the light-dark cycle.

netics (Rivière et al, 1999), and approached the value that would be expected for a comparable dose in humans (16$17 \mu \mathrm{Mh}$ (Cook et al, 1993). A more comparable maximum concentration and AUC would have resulted if the two species have similar volumes of distribution. In fact, although most human studies have consistently reported $V_{\mathrm{d}}$ values near $3.6 \mathrm{l} / \mathrm{kg}$ (Cook et al, 1993; Mendelson et al, 1995; Harris et al, 2003a), values as high as $91 / \mathrm{kg}$ have been estimated in the rat (Hutchaleelaha and Mayersohn, 1996; Rivière et al, 1999, 2000; Cho et al, 2001; Kitaichi et al, 2003); a higher $V_{\mathrm{d}}$ in the rat could explain the lower plasma concentration and AUC which we found.

It should be noted that the dynamic infusion procedure does not attempt to simulate the relatively rapid fall in plasma concentration associated with the METH distribution phase. However, because of the high lipid solubility of METH, the rate of rise in brain concentrations should be similar for the two species, and, in fact, the qualitative features of the distribution phase are similar (Cook et al, 1993; Cho et al, 2001). Despite this potential difference, our results do demonstrate that with the dynamic infusion procedure, the general magnitude, and duration of drug exposure in the rat can be made to approximate the profile in humans. In contrast, with other experimental procedures used to simulate continuous drug administration (eg pellet/ minipump implants), significant differences are apparent with regard to both the initial rate of drug accumulation (ie slower than from typical routes used by METH abusers) and the temporal pattern of drug exposure (ie more constantly maintained levels than occurs in humans). Our pharmaco- kinetic data indicate that the dynamic infusion procedure produces a plasma METH profile that more closely resembles the profile that occurs in humans.

\section{Behavioral Profile}

The single daily dynamic infusion paradigm produced a behavioral profile in the rat that exhibited several characteristics that have been associated with the human response to the drug, including evidence of psychomotor stimulation, sensitization, and both within- and across-day tolerance. Controlled studies in humans have shown that acute administration of low AMPH doses produces subjective effects like euphoria, 'mind racing', and alertness (Angrist et al, 1987; Angrist, 1987; McTavish et al, 1999; Vollm et al, 2004); physiological changes in heart rate and blood pressure have also been monitored (Griffith and Gunne, 1977; Brown et al, 1978; Angrist et al, 1987; Angrist, 1987; Cook et al, 1993; Oswald et al, 2005). In many of these studies, when the time course of these stimulant-induced alterations was determined, a dissociation between these effects and measured or inferred plasma levels was apparent and often referred to as acute tolerance or tachyphylaxis (Angrist et al, 1987; Angrist, 1987; Cook et al, 1993; Swanson et al, 2002; Greenhill et al, 2003; Foltin and Haney, 2004). We observed a similar drug-behavior dissociation during the first treatment day. That is, although our results indicated that the drug-induced increase in locomotion appeared to initially parallel plasma METH levels, by about $16 \mathrm{~h}$ (0200 hours, Figure 4), behavioral activation was no 
a

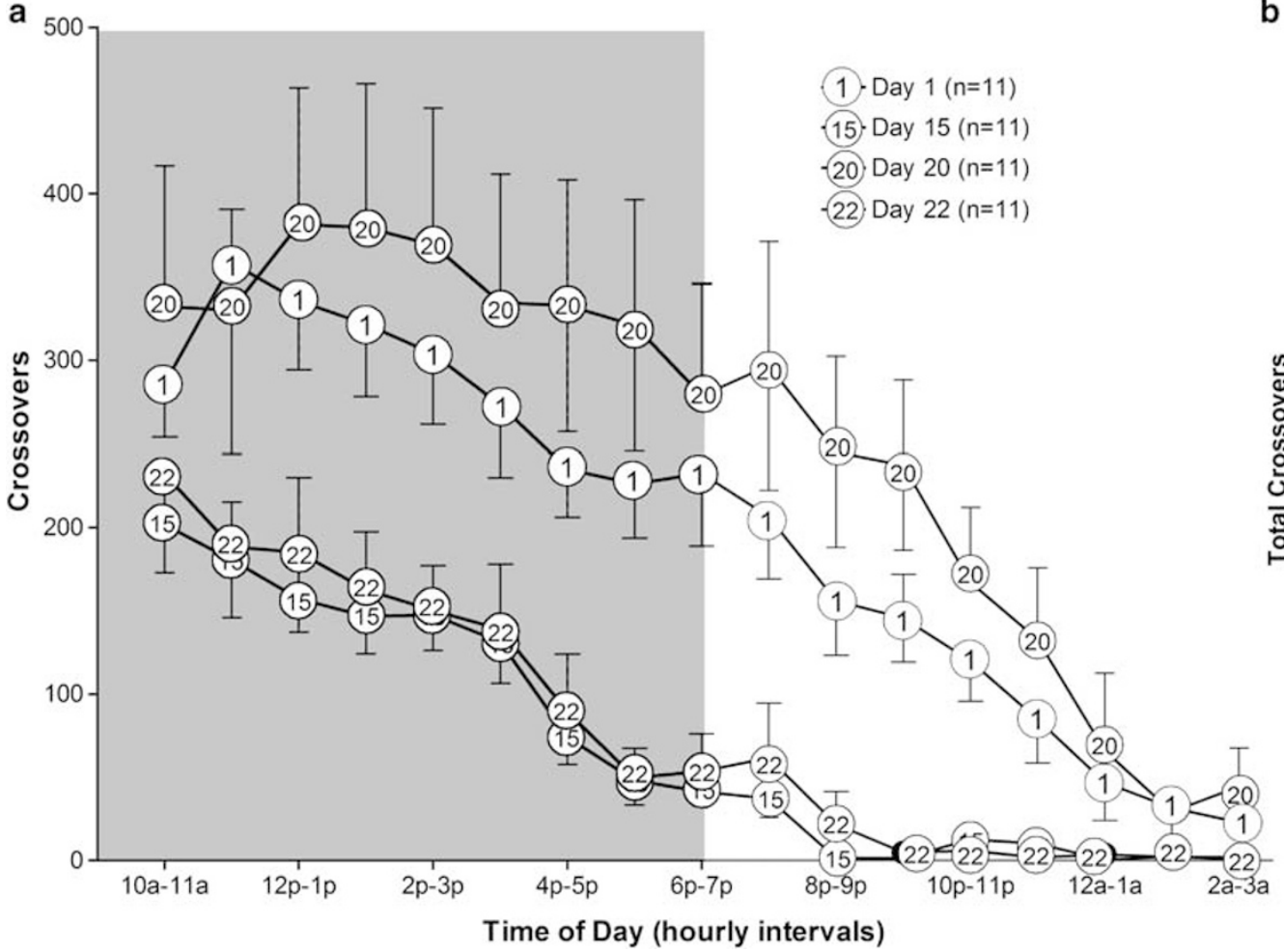

b

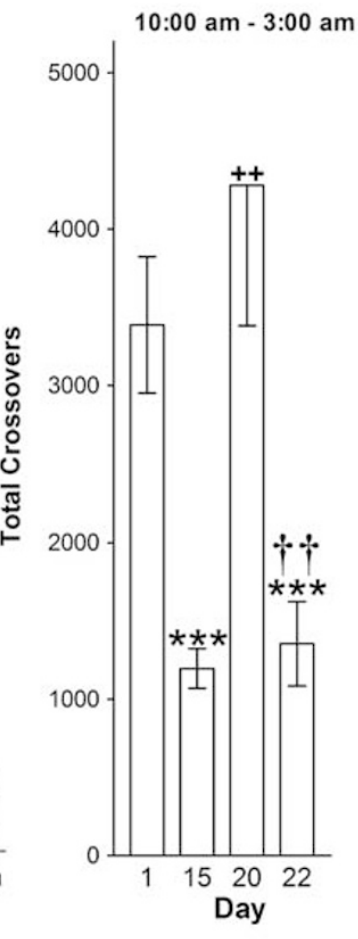

Figure 7 (a) Locomotor response to dynamic infusion of METH $(0.5 \mathrm{mg} / \mathrm{kg})$ on the Ist (Day 20) and 3rd (Day 22) day of the post-treatment challenge. Numbers in parentheses indicate the number of animals in each group. Responses of the same animals on the Ist and I5th day of the single daily dynamic infusion pretreatment are included for comparison purposes. Values are presented as mean crossovers \pm SEM. The number within each open circle indicates the treatment day. Shading represents the dark/active phase of the light-dark cycle. (b) Histograms represent cumulated crossovers over the indicated interval. $* * * * 0.001$ compared to Day I; ${ }^{+}+p<0.0$ I compared to Day I5; and ${ }^{\dagger \dagger} p<0.0$ I compared to Day 20.

longer detectable. Importantly, plasma levels remained relatively high even when the animals appeared to be asleep, and, in fact, preliminary evidence from a separate study showed that dynamic infusion of a lower dose of METH $(0.125 \mathrm{mg} / \mathrm{kg})$, estimated to produce peak plasma levels less than those present at the 0200 hours time point following dynamic infusion of $0.5 \mathrm{mg} / \mathrm{kg}$, resulted in a significant and relatively long-lasting increase in locomotor activation (crossovers, $0-120 \mathrm{~min}$ after the start of dynamic infusion: SALINE: $32 \pm 3$; METH: $66 \pm 5 ; \mathrm{t}=6.9, p \leqslant 0.001$ ). These findings suggest that pharmacodynamic adaptations, which occurred during the course of continuous drug exposure, might account for the apparent dissociation between the plasma drug levels and behavioral activity at these later time intervals. Several clinical researchers have speculated that the acute tolerance might be due to DA depletion at critical brain sites and/or downregulation of DA receptors (Angrist, 1987; Vollm et al, 2004). In this regard, our results showed that the acute striatal extracellular DA response was significantly shorter than would be expected from the pharmacokinetic data, and therefore, this apparent pharmacodynamic alteration could, at least partially, underlie the acute tolerance reflected in the measure of behavioral activation we monitored.

Repeated dynamic infusions produced a progression of behavioral changes, a prominent component of which was sensitization, primarily in the form of increasingly more intense and continuous stereotypy up to about the 10th day of treatment; the magnitude of the locomotor activity displayed a corresponding decline during this period of repeated dynamic infusions. It has been well established by a large body of preclinical research that behavioral sensitization is reliably produced by repeated, intermittent s.c. or intraperitoneal (i.p.) stimulant administration, and that, depending on dose, this effect is expressed as increased locomotor activity and/or stereotyped behaviors (see, Segal and Mandell, 1974; Segal and Schuckit, 1983; Robinson and Becker, 1986, for reviews). However, unlike most of these studies, with dynamic infusion there was a gradual increment in plasma drug level across successive treatment days. Therefore, it could be argued that the behavioral augmentation we observed was at least, in part, due to a progressive increase in dose. However, with our treatment paradigm, most of the increment in plasma METH occurred within the first 3 days, with about $80 \%$ of the total dose increase apparent by Day 2 (Table 1, Figure 2). In contrast, the amount of time animals spent engaged in stereotypy was not significantly different between Days 1 and 2. Furthermore, a significant increase in oral stereotypy occurred between Days 5 and 10, during which time the dose level had effectively stabilized. Therefore, the increment in drug level does not appear to 

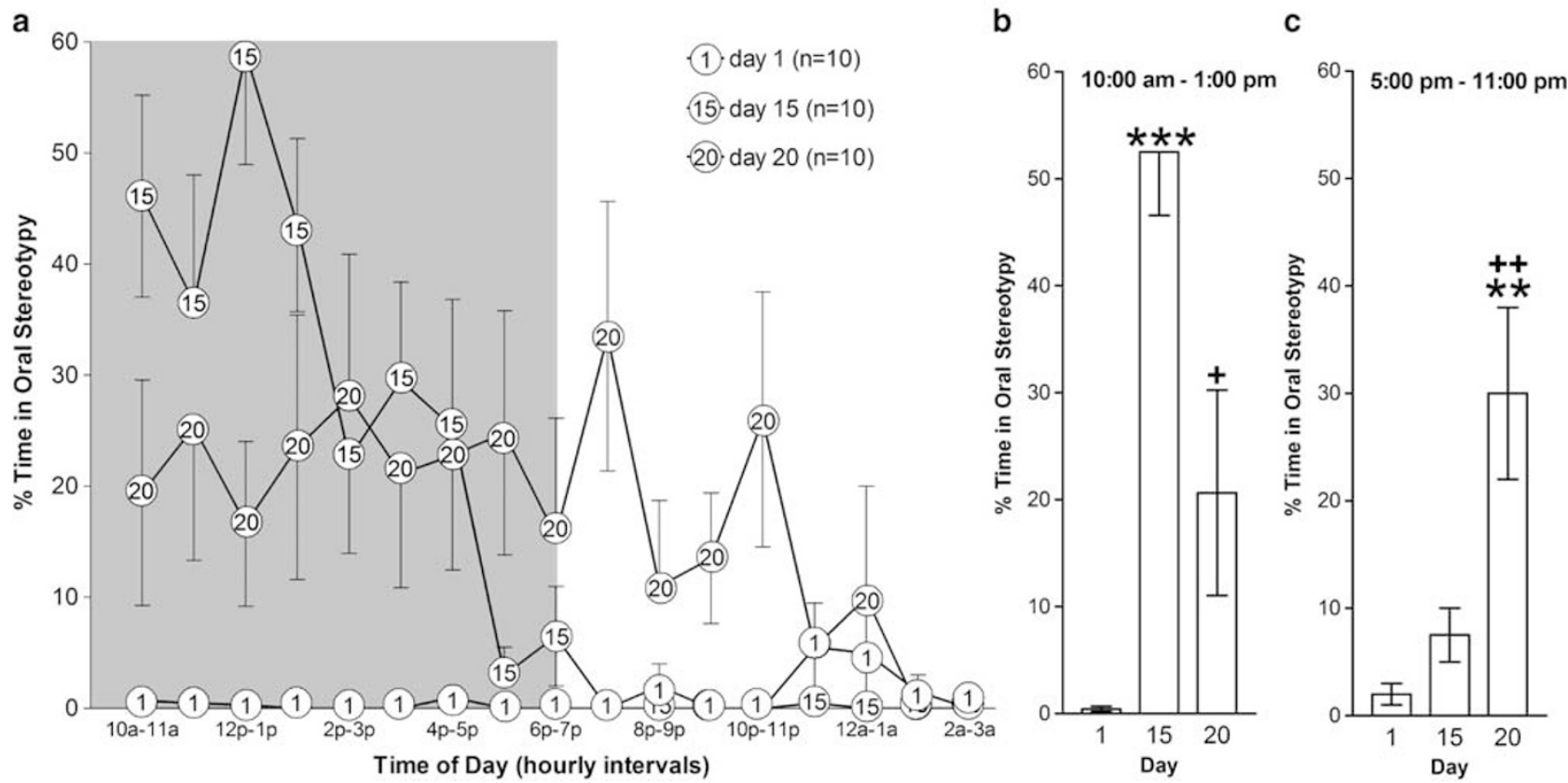

Figure 8 Oral stereotypy response to dynamic infusion of METH $(0.5 \mathrm{mg} / \mathrm{kg})$ on the Ist (Day I) and I5th (Day I5) day of single daily treatment compared to the Ist (Day 20) day of the post-treatment challenge. Numbers in parentheses indicate the number of animals in each group. The response on Day 22 was identical to the response on Day 15, and for the sake of clarity was not included in the figure. Each value represents the percent of time of the indicated interval during which the animal exhibited oral stereotypy, and is presented as means \pm SEM. The number within each open circle indicates the treatment day. Shading represents the dark/active phase of the light-dark cycle. (b) Histograms represent cumulated stereotypy over the indicated interval. *** $p<0.0$ I, $* * * * 0<0.00$ I compared to Day I; ${ }^{+} p<0.05,{ }^{+}+p<0.0$ I compared to Day I 5.

account for the most pronounced behavioral augmentation we observed.

Concurrent with sensitization, which persisted throughout the single daily treatment, a marked decrease in the duration of behavioral activation became increasingly apparent in the daily responses after Day 10 of drug administration. We previously observed a similar behavioral profile in studies using a paradigm of repeated high-dose METH or AMPH 'binge' treatments (Segal and Kuczenski, 1997a, b, 1999). In our experience, single daily s.c. injections do not result in a shortened response; therefore, it appears that more continuous drug exposure is a critical factor underlying the ultimate occurrence of this form of response tolerance or emergent tachyphylaxis. Consistent with this notion, a recent report showed that repeated, relatively prolonged periods of stimulant self-administration was associated with a loss of behavioral sensitization in rats, whereas evidence of sensitization was prominent with shorter, more typical self-administration regimens (Ben Shahar et al, 2004). Interestingly, sensitization and/or tolerance as a function of repeated stimulant administration have been reported in controlled human studies (Strakowski et al, 1996, 2001; Strakowski and Sax, 1998; Wachtel and De Wit, 1999; Comer et al, 2001). However, in these studies relatively low, oral doses were used and self-ratings of subjective effects were assessed; therefore, it is difficult to relate these finding to the behavioral changes we observed with our treatment procedures.

In addition to the development of sensitization and tolerance to various features of the response, we also observed qualitative changes that gradually emerged through the course of treatment, and consisted of a transformation in the expression of locomotion to brief relatively episodic bursts of activity that interrupted long intervals of continuous, intense stereotypy. By Day 10 of the dynamic infusion treatment, such periodic, often 'explosive' movements represented most of the ambulation that occurred. As we previously described in the context of multiple daily high-dose s.c. METH or AMPH administration (Segal and Kuczenski, 1997a, b, 1999), this emergent feature of the behavior was not evident in the acute response to any dose of AMPH or METH we have characterized (Segal and Kuczenski, 1997a,b). Therefore, it appears that multiple daily high dose treatment, or, as we have now shown, the repeated fluctuating pattern of relatively continuous METH exposure is required to elicit this qualitative change in behavior.

\section{Neurochemical Profile}

Evidence suggests that many of the behavioral effects of METH depend on its release of striatal DA. Furthermore, the dorsal striatum appears to be particularly vulnerable to long-term METH exposure (see, Davidson et al, 2001; Cadet et al, 2003, for reviews). Therefore, we characterized the caudate extracellular DA response during the first and fifteenth dynamic infusion of $0.5 \mathrm{mg} / \mathrm{kg}$ METH. The magnitude of the initial DA response peak was within the range expected for acute i.v. administration of AMPHs (Cho et al, 1999). However, the relatively rapid decline that 
subsequently occurred did not parallel the slower reduction in plasma METH; that is, extracellular DA decreased by almost $50 \%$ during the initial $2 \mathrm{~h}$ as compared to less than $10 \%$ for plasma METH (Figures 3 and 6). Furthermore, although the rate of DA decline more closely followed the decline in plasma METH during the $2-24 \mathrm{~h}$ time period, there was no close association between concentration of the drug and the anticipated extracellular transmitter during the remainder of the response. These findings are in contrast to our previous observations of parallel extracellular DA and plasma stimulant concentration, using more traditional injection techniques (Kuczenski et al, 1997a; Cho et al, 1999). Thus, a significant dissociation between the temporal profiles of extracellular DA and plasma METH was revealed with the dynamic infusion procedure.

One possible explanation for the rapid decline in DA during the initial $2 \mathrm{~h}$ of dynamic infusion of $0.5 \mathrm{mg} / \mathrm{kg}$ METH stems from evidence that METH-induced DA release depends on the functional availability of DAT, and that DAT availability can be regulated by rapid endocytotic trafficking (see, Zahniser and Sorkin, 2004, for a review). Of particular relevance, recent studies of the human DAT in embryonic kidney cells (Saunders et al, 2000) indicate that AMPH and/ or high extracellular DA can promote a concentrationdependent internalization of the DAT, thereby reducing DA transport capacity, and thus the availability of the DAT to participate in not only uptake of synaptic transmitter but also METH-induced release of cytoplasmic DA from the nerve terminal. Interestingly, the temporal characteristics of DAT internalization in these studies were similar to the rate of decline in extracellular DA we observed during the initial stages of METH dynamic infusion. Thus, it could be argued that drug-induced rapid internalization of DAT may contribute to the pronounced dissociation between DA responsivity and drug concentration during the early stages of the response.

Although after about $2 \mathrm{~h}$ following the start of $\mathrm{METH}$ infusion the rate of decline in extracellular DA had diminished, a significant dissociation between plasma METH and DA responsivity persisted throughout the remainder of the drug exposure. This dissociation was exemplified by the observation that within $22 \mathrm{~h}$ of the initiation of the dynamic infusion, extracellular DA was no longer significantly elevated above baseline in spite of our evidence that a pharmacologically active plasma METH concentration continued to be present. At least two possible mechanisms may have contributed to this apparent tachyphylaxis. First, the cytoplasmic pool of DA may have been significantly diminished by the sustained presence of $\mathrm{METH}$, thus attenuating the drug-induced release of transmitter. However, by the 22-h time point, the DA metabolite, DOPAC, had recovered to predrug levels. This observation suggests that the releasable pool of transmitter had been replenished, since DOPAC originates primarily from the metabolism of cytoplasmic DA (Roffler-Tarlov et al, 1971; Westerink and Korf, 1976). Alternatively, it is possible that DAT internalization, once promoted by the initial high extracellular transmitter concentrations, persisted throughout the drug response even after METH levels significantly declined. Future studies will be required to determine the time course for
DAT internalization under conditions of changing METH concentrations.

Comparison of the temporal patterns of extracellular caudate DA, assessed on the 1st and 15th day of dynamic infusion in the same animals, revealed that with repeated METH treatments DA concentrations were significantly greater through most of the response. One factor that might account for this enhanced DA response is the elevated plasma METH levels on Day 15 relative to Day 1 (see Figure 2, Table 1). Residual drug arising from the near 12-h METH half-life results in an effective increase in METH dose, which would be expected to increase DA levels during repeated drug administrations. In addition, although there are conflicting results in the literature (eg Kuczenski et al, 1997b), some previous research suggests that repeated, intermittent stimulant regimens using conventional drug administration procedures result in an increased caudate DA response, possibly due to compensatory adjustments that enhance the responsivity of DA neurons to stimulants (see, Arai et al, 1996, for a review). Thus, the mechanisms underlying sensitization-related enhanced DA release may also be implicated in the DA response elevation we observed with single daily dynamic infusions. However, the absence of a significant DA increase during the initial response (first $30 \mathrm{~min}$, Figure 6) is difficult to explain in the context of either elevated plasma METH or a sensitized DA release, particularly since the behavior exhibited a marked sensitization during this time period. In addition, baseline DA levels prior to the initiation of the Day 15 dynamic infusion were significantly elevated. Although residual METH (estimated to be approximately $0.18 \mu \mathrm{M}$ at this time point; see Table 1) might be invoked to explain the increased baseline, similar plasma METH levels failed to support increased extracellular DA during the final sampling intervals of the Day 1 dynamic infusion (Figure 6). It is apparent, therefore, that further studies will be required to identify the various factors that may influence the changes in the DA response, which develop with repeated dynamic infusions. In particular, it will be important to determine if the DA response increase as revealed on Day 15 has, in fact, fully emerged within the first several days of treatment, thus suggesting that the increment in plasma METH levels is primarily responsible for the elevation in DA.

\section{DA-Behavior Relationships}

The increased DA response that occurred with repeated single daily infusions may have contributed significantly to the progressive changes in the behavioral response across treatment days. However, as discussed previously, to the extent that incremental dose is responsible for the elevated DA response, it would be expected that most of the behavioral changes would have occurred within the first several days of METH administration, corresponding to the rate of increase of plasma drug levels (Table 1, Figure 2). Therefore, it would be difficult to reconcile a drug concentration-dependent increase in DA with the progressive behavioral sensitization that continued up to at least Day 10 of treatment. Rather, the DA response increase may have continued after the plasma METH pattern had stabilized. In addition, adaptations in striatal postsynaptic mechanisms and/or effects of METH on other DA systems 
may also have contributed to the enhanced behavioral responsiveness that was produced by this treatment.

Neither the observed changes in DA release nor in plasma METH levels are consistent with the pronounced shortening of the behavioral activation that was particularly evident by Day 15. On this day, METH-induced focused stereotypies had subsided and all animals were sleeping by about $2000-$ 2100 hours, at a time when plasma METH concentrations and caudate extracellular DA were still substantially elevated. In fact, extracellular DA at this time point on Day 15 (Figure 6) was about $120 \mathrm{nM}$, sufficient to support marked locomotor activation on Day 1. Therefore, postsynaptic alterations may have contributed to the tolerance that developed with repeated dynamic infusions. Although downregulation of DA receptors has not been consistently associated with repeated stimulant administration using traditional rodent treatment regimens, we recently reported small but significant decreases in radioligand binding to striatal D1 and D2 DA receptors following prolonged exposure to day-long i.v. METH administration (Segal et al, 2005). In addition, O'Connor et al (2005) recently reported that repeated administration of the long-acting DAT inhibitor, WF-23, resulted in a progressive reduction in striatal D2 receptor-stimulated $\left[{ }^{35} \mathrm{~S}\right] \mathrm{GTP} \gamma \mathrm{S}$ binding, and a parallel decline in WF-23-stimulated locomotor activation over the 21 days of treatment. Importantly, no changes in D2 receptor G-protein coupling or tolerance to the locomotor activation were evident until 7 days of treatment. These results further support the view that in addition to the chronicity of drug treatment, the duration of each exposure may be a significant factor in determining the nature of the behavioral and neurochemical adaptations that develops with repeated drug exposure.

However, it is important to note that, in the current study, we only characterized the dorsal striatal temporal DA response profiles on Day 1 and Day 15. Although our previous observations indicated that the extracellular DA response patterns to the AMPHs in the dorsal and ventral striatum are similar (Kuczenski et al, 1991, 1997b; Segal and Kuczenski, 1992; Kuczenski and Segal, 1992), it is conceivable that dynamic infusions of the drug result in different temporal profiles in the two striatal regions. This possibility is particularly important since a great deal of converging evidence suggests that stimulant effects on DA transmission in the dorsal and ventral striatum modulate different behavioral components of the stimulant response (Roberts et al, 1975; Costall and Naylor, 1977; Swerdlow et al, 1986; Dickson et al, 1994). Therefore, changes we observed in the relative expression of locomotion and stereotypy, both within and between days may have been due, at least partially, to different region-related effects on the pattern of DA transmission. Furthermore, although beyond the scope of the current studies, it is also important to note that METH effects on mechanisms regulating circadian rhythms may have contributed to both the qualitative and quantitative behavioral changes we observed.

\section{Persistence of Behavioral Effects}

The response of METH-pretreated animals to subsequent METH challenge revealed evidence that both sensitization and tolerance persisted after a relatively short drug with- drawal period. That relatively continuous, intense stereotypy appeared during the first day of challenge, further indicating that mechanisms other than incremental plasma METH concentration were responsible for the sensitization observed during the single daily dynamic infusion treatment. Furthermore, although neither the magnitude nor the duration of locomotor activation diminished, observations revealed that the locomotion occurred primarily in the form of episodic bursts of ambulation, whereas this qualitative change in behavior did not emerge during pretreatment until the 5-10th drug administration. However, while sensitization, along with qualitative behavioral changes, was clearly apparent during the first challenge day, the reemergence of tolerance was not obvious until animals received additional days of treatment. By the third drug challenge day, neither the qualitative features of the behavior nor the magnitude or duration of the response were significantly different from the response on the 15th pretreatment day. Thus, as with sensitization, tolerance also endured after cessation of single daily dynamic infusions of METH. The mechanisms underlying these persistent effects remain to be elucidated.

In conclusion, this series of studies has demonstrated the feasibility of using a repeated dynamic infusion protocol designed to produce a pattern of continuous METH exposure with a frequency and magnitude of fluctuation, as well as incremental dose characteristics, that approximate the temporal pattern of change in plasma METH levels expected to occur in humans treated with the same drug regimen. Our results showed that, using this treatment paradigm, elements of sensitization and tolerance, as well as qualitative changes in the response occurred, and that these chronic METH-induced effects developed with different temporal profiles. Furthermore, the mechanisms underlying these various response characteristics endured for at least 3 days after discontinuation of drug treatment; however, fewer days of METH re-exposure were required for the expression of sensitization than for the reappearance of tolerance. Importantly, this combination of behavioral features is not found with repeated daily METH treatments using other more traditional administration procedures. Although a DA response increase may contribute to the behavioral response augmentation, other mechanisms, perhaps involving DA receptor desensitization, must be implicated in the tolerance that developed with more prolonged treatment. Our results suggest that simulation of human METH exposure patterns may be necessary to more accurately reproduce the neurobiological and behavioral effects of METH administration in humans.

\section{ACKNOWLEDGEMENTS}

This research was supported by NIH Grants DA-01568 and DA-02854.

\section{REFERENCES}

Anggard E, Jonsson LE, Hogmark AL, Gunne LM (1973). Amphetamine metabolism in amphetamine psychosis. Clin Pharmacol Ther 14: 870-880.

Angrist B (1987). Clinical effects of central nervous system stimulants: a selective update. In: Engel J, Oreland L (eds). 
Brain Reward Systems and Abuse. Raven Press: New York. pp 109-127.

Angrist B (1994). Amphetamine psychosis: clinical variations of the syndrome. In: Cho AK, Segal DS (eds). Amphetamine and its Analogues. Academic Press: San Diego. pp 387-414.

Angrist B, Corwin J, Bartlik B, Cooper T (1987). Early pharmacokinetics and clinical effects of oral D-amphetamine in normal subjects. Biol Psychiatry 22: 1357-1368.

Arai I, Shimazoe T, Shibata S, Inoue H, Yoshimatsu A, Watanabe S (1996). Enhancement of dopamine release from the striatum through metabotropic glutamate receptor activation in methamphetamine sensitized rats. Brain Res 729: 277-280.

Ben Shahar O, Ahmed SH, Koob GF, Ettenberg A (2004). The transition from controlled to compulsive drug use is associated with a loss of sensitization. Brain Res 995: 46-54.

Brown WA, Corriveau DP, Ebert MH (1978). Acute psychologic and neuroendocrine effects of dextroamphetamine and methylphenidate. Psychopharmacology 58: 189-195.

Cadet JL, Jayanthi S, Deng XL (2003). Speed kills: cellular and molecular bases of methamphetamine-induced nerve terminal degeneration and neuronal apoptosis. FASEB J 17: 1775-1788.

Cho AK, Melega WP, Kuczenski R, Segal DS (2001). Relevance of pharmacokinetic parameters in animal models of methamphetamine abuse. Synapse 39: 161-166.

Cho AK, Melega WP, Kuczenski R, Segal DS, Schmitz DA (1999). Caudate-putamen dopamine and stereotypy response profiles after intravenous and subcutaneous amphetamine. Synapse 31: 125-133.

Comer SD, Hart CL, Ward AS, Haney M, Foltin RW, Fischman MW (2001). Effects of repeated oral methamphetamine administration in humans. Psychopharmacology 155: 397-404.

Cook CE, Jeffcoat AR, Hill JM, Pugh DE, Patetta PK, Sadler BM et al (1993). Pharmacokinetics of methamphetamine selfadministered to human subjects by smoking S-(+)-methamphetamine hydrochloride. Drug Metab Dispos 21: 717-723.

Cook CE, Jeffcoat AR, Sadler BM, Hill JM, Voyksner RD, Pugh DE et al (1992). Pharmacokinetics of oral methamphetamine and effects of repeated daily dosing in humans. Drug Metab Dispos 20: $856-862$.

Costall B, Naylor RJ (1977). Mesolimbic and extrapyramidal sites for the mediation of stereotyped behavior patterns and hyperactivity by amphetamine and apomorphine in the rat. In: Ellinwood EH Jr, Kilbey MJ (eds). Cocaine and Other Stimulants. Plenum Press: New York. pp 47-76.

Cryan JF, Hoyer D, Markou A (2003). Withdrawal from chronic amphetamine induces depressive-like behavioral effects in rodents. Biol Psychiatry 54: 49-58.

Davidson C, Gow AJ, Lee TH, Ellinwood Jr EH (2001). Methamphetamine neurotoxicity: necrotic and apoptotic mechanisms and relevance to human abuse and treatment. Brain Res Rev 36: 1-22.

Devoto P, Flore G, Pira L, Longu G, Gessa GL (2004). Alpha ${ }_{2}$ adrenoceptor mediated co-release of dopamine and noradrenaline from noradrenergic neurons' in the cerebral cortex. J Neurochem 88: 1003-1009.

Dickson PR, Lang CG, Hinton SC, Kelley AE (1994). Oral stereotypy induced by amphetamine microinjection into striatum: an anatomical mapping study. Neuroscience 61: 81-91.

Ellinwood Jr EH, Lee TH (1983). Effect of continuous systemic infusion of $\mathrm{D}$-amphetamine on the sensitivity of nigral dopamine cells to apomorphine inhibition of firing rates. Brain Res 273: 379-383.

Ellison G, Eison MS, Huberman HS, Daniel F (1978). Long-term changes in dopaminergic innervation of caudate nucleus after continuous amphetamine administration. Science 201: 276-278.

Ernst T, Chang L, Leonido-Yee M, Speck O (2000). Evidence for long-term neurotoxicity associated with methamphetamine abuse - a ${ }^{1}$ H MRS study. Neurology 54: 1344-1349.
Foltin RW, Haney M (2004). Intranasal cocaine in humans: acute tolerance, cardiovascular and subjective effects. Pharmacol Biochem Behav 78: 93-101.

Ghitza UE, Fabbricatore AT, Prokopenko V, Pawlak AP, West MO (2003). Persistent cue-evoked activity of accumbens neurons after prolonged abstinence from self-administered cocaine. J Neurosci 23: 7239-7245.

Greenhill LL, Swanson JM, Steinhoff K, Fried J, Posner K, Lerner M et al (2003). A pharmacokinetic/pharmacodynamic study comparing a single morning dose of adderall to twice-daily dosing in children with ADHD. J Am Acad Child Adolesc Psychiatry 42: 1234-1241.

Griffith JD, Gunne LM (1977). Effects of amphetamines in humans. In: Martin JR (ed). Drug Addiction II. Springer-Verlag: New York. pp 247-275.

Gygi MP, Gygi SP, Johnson M, Wilkins DG, Gibb JW, Hanson GR (1996). Mechanisms for tolerance to methamphetamine effects. Neuropharmacology 35: 751-757.

Harris DS, Boxenbaum H, Everhart ET, Sequeira G, Mendelson JE, Jones RT (2003a). The bioavailability of intranasal and smoked methamphetamine. Clin Pharmacol Ther 74: 475-486.

Harris DS, Reus VI, Wolkowitz OM, Mendelson JE, Jones RT (2003b). Altering cortisol level does not change the pleasurable effects of methamphetamine in humans. Neuropsychopharmacology 28: 1677-1684.

Hutchaleelaha A, Mayersohn M (1996). Influence of activated charcoal on the disposition kinetics of methamphetamine enantiomers in the rat following intravenous dosing. J Pharm Sci 85: 541-545.

Kalechstein AD, Newton TF, Green M (2003). Methamphetamine dependence is associated with neurocognitive impairment in the initial phases of abstinence. J Neuropschiatry Clin Neurosci 15: 215-220.

Kitaichi K, Morishita Y, Doi Y, Ueyama J, Matsushima M, Zhao YL et al (2003). Increased plasma concentration and brain penetration of methamphetamine in behaviorally sensitized rats. Eur J Pharmacol 464: 39-48.

Kuczenski R, Melega WP, Cho AK, Segal DS (1997a). Extracellular dopamine and amphetamine following systemic amphetamine administration: comparison to the behavioral response. J Pharmacol Exp Ther 282: 591-596.

Kuczenski R, Segal DS (1989). Concomitant characterization of behavioral and striatal neurotransmitter response to amphetamine using in vivo microdialysis. J Neurosci 9: 2051-2065.

Kuczenski R, Segal DS (1992). Differential effects of amphetamine and dopamine uptake blockers (cocaine, nomifensine) on caudate and accumbens dialysate dopamine and 3-methoxytyramine. J Pharmacol Exp Ther 262: 1085-1094.

Kuczenski R, Segal DS, Aizenstein ML (1991). Amphetamine, fencamfamine, and cocaine: relationships between locomotor and stereotypy response profiles and caudate and accumbens dopamine dynamics. J Neurosci 11: 2703-2712.

Kuczenski R, Segal DS, Todd PK (1997b). Behavioral sensitization and extracellular dopamine responses to amphetamine after various treatments. Psychopharmacology 134: 221-229.

McCann UD, Wong DF, Yokoi F, Villemagne V, Dannals RF, Ricaurte GA (1998). Reduced striatal dopamine transporter density in abstinent methamphetamine and methcathinone users: evidence from positron emission tomography studies with $\left[{ }^{11} \mathrm{C}\right] \mathrm{WIN}-35$ 428. J Neurosci 18: 8417-8422.

McTavish SFB, McPherson MH, Sharp T, Cowen PF (1999). Attenuation of some subjective effects of amphetamine following tyrosine depletion. J Psychopharmacol 13: 144-147.

Melega WP, Williams AE, Schmitz DA, DiStefano EW, Cho AK (1995). Pharmacokinetic and pharmacodynamic analysis of the actions of D-amphetamine and D-methamphetamine on the dopamine terminal. J Pharmacol Exp Ther 274: 90-96. 
Mendelson J, Jones RT, Upton R, Jacob III P (1995). Methamphetamine and ethanol interactions in humans. Clin Pharmacol Ther 57: 559-568.

O’Connor KA, Porrino LJ, Davies HML, Childers SR (2005). Timedependent changes in receptor/G-protein coupling in rat brain following chronic monoamine transporter blockade. J Pharmacol Exp Ther 313: 510-517.

Ornstein TJ, Iddon JL, Baldacchino AM, Sahakian BJ, London M, Everitt BJ et al (2000). Profiles of cognitive dysfunction in chronic amphetamine and heroin abusers. Neuropsychopharmacology 23: 113-126.

Oswald LM, Wong DF, McCaul M, Zhou Y, Kuwabara H, Choi L et al (2005). Relationships among ventral striatal dopamine release, cortisol secretion, and subjective responses to amphetamine. Neuropsychopharmacology 30: 821-832.

Perez-Reyes M, White WR, McDonald SA, Hicks RE, Jeffcoat AR, Hill JM et al (1991). Clinical effects of daily methamphetamine administration. Clin Neuropharmacol 14: 352-358.

Rivière GJ, Byrnes KA, Gentry WB, Owens SM (1999). Spontaneous locomotor activity and pharmacokinetics of intravenous methamphetamine and its metabolite amphetamine in the rat. J Pharmacol Exp Ther 291: 1220-1226.

Rivière GJ, Gentry WB, Owens SM (2000). Disposition of methamphetamine and its metabolite amphetamine in brain and other tissues in rats after intravenous administration. J Pharmacol Exp Ther 292: 1042-1047.

Roberts DCS, Zis AP, Fibiger HC (1975). Ascending catecholamine pathways and amphetamine induced locomotion: importance of dopamine and apparent noninvolvement of norepinephrine. Brain Res 93: 441-454.

Robinson TE, Becker JB (1986). Enduring changes in brain and behavior produced by chronic amphetamine administration: a review and evaluation of animal models of amphetamine psychosis. Brain Res Rev 11: 157-198.

Robinson TE, Whishaw IQ (1988). Normalization of extracellular dopamine in striatum following recovery from a partial unilateral 6-OHDA lesion of the substantia nigra: a microdialysis study in freely moving rats. Brain Res 450: 209-224.

Roffler-Tarlov S, Sharman D, Tegerdine P (1971). 3,4-Dihydroxyphenyl-acetic acid in the mouse striatum: a reflection of intraand extra-neuronal metabolism of dopamine? Br J Pharmacol 42: 343-351.

Samaha A-N, Mallet N, Ferguson SM, Gonon F, Robinson TE (2004). The rate of cocaine administration alters gene regulation and behavioral plasticity: implications for addiction. J Neurosci 24: 6362-6370.

Saunders C, Ferrer JV, Shi L, Chen JY, Merrill G, Lamb ME et al (2000). Amphetamine-induced loss of human dopamine transporter activity: an internalization-dependent and cocainesensitive mechanism. Proc Natl Acad Sci USA 97: 68506855.

Schmidt CJ, Gehlert DR, Peat MA, Sonsalla PK, Hanson GR, Wamsley JK et al (1985). Studies on the mechanism of tolerance to methamphetamine. Brain Res 343: 305-313.

Segal DS, Kuczenski R (1987). Individual differences in responsiveness to single and repeated amphetamine administration: behavioral characteristics and neurochemical correlates. J Pharmacol Exp Ther 242: 917-926.

Segal DS, Kuczenski R (1992). In vivo microdialysis reveals a diminished amphetamine-induced dopamine response corresponding to behavioral sensitization produced by repeated amphetamine pretreatment. Brain Res 571: 330-337.

Segal DS, Kuczenski R (1997a). An escalating dose 'binge' model of amphetamine psychosis: behavioral and neurochemical characteristics. J Neurosci 17: 2551-2566.
Segal DS, Kuczenski R (1997b). Repeated binge exposure to amphetamine and methamphetamine: behavioral and neurochemical characterization. J Pharmacol Exp Ther 282: 561-573.

Segal DS, Kuczenski R (1999). Escalating dose/binge stimulant exposure: relationship between emergent behavioral profile and differential caudate-putamen/nucleus accumbens dopamine responses. Psychopharmacology 142: 182-192.

Segal DS, Kuczenski R, O’Neil ML, Melega WP, Cho AK (2005). Prolonged exposure to intravenous methamphetamine: behavioral and neurochemical characterization. Psychopharmacology 180: $501-512$.

Segal DS, Mandell AJ (1974). Long-term administration of Damphetamine: progressive augmentation of motor activity and stereotypy. Pharmacol Biochem Behav 2: 249-255.

Segal DS, Schuckit MA (1983). Animal models of stimulant-induced psychosis. In: Creese I (ed). Stimulants: Neurochemical, Behavioral and Clinical Perspectives. Raven Press: New York. pp 131-167.

Sekine Y, Iyo M, Ouchi Y, Matsunaga T, Tsukada H, Okada $\mathrm{H}$ et al (2001). Methamphetamine-related psychiatric symptoms and reduced brain dopamine transporters studied with PET. Am J Psychiatry 158: 1206-1214.

Simon SL, Domier CP, Sim T, Richardson K, Rawson RA, Ling W (2002). Cognitive performance of current methamphetamine and cocaine abusers. J Addict Dis 21: 61-74.

Strakowski SM, Sax KW (1998). Progressive behavioral response to repeated d-amphetamine challenge: further evidence for sensitization in humans. Biol Psychiatry 44: 1171-1177.

Strakowski SM, Sax KW, Rosenberg HL, DelBello MP, Adler CM (2001). Human response to repeated low-dose D-amphetamine: evidence for behavioral enhancement and tolerance. Neuropsychopharmacology 25: 548-554.

Strakowski SM, Sax KW, Setters MJ, Keck Jr PE (1996). Enhanced response to repeated D-amphetamine challenge: evidence for behavioral sensitization in humans. Biol Psychiatry 40: 872-880.

Swanson JM, Lerner M, Wigal T, Steinhoff K, Greenhill LL, Posner K et al (2002). The use of a laboratory school protocol to evaluate concepts about efficacy and side effects of new formulations of stimulant medications. J Atten Disord 6(Suppl 1): S73-S88.

Swerdlow NR, Vaccarino FJ, Amalric M, Koob GF (1986). The neural substrates for the motor-activating properties of psychostimulants: a review of recent findings. Pharmacol Biochem Behav 25: 233-248.

Thompson PM, Hayashi KM, Simon SL, Geaga JA, Hong MS, Sui Y et al (2004). Structural abnormalities in the brains of human subjects who use methamphetamine. J Neurosci 24: 6028-6036.

Volkow ND, Chang L, Wang GJ, Fowler JS, Franceschi D, Sedler MJ et al (2001). Higher cortical and lower subcortical metabolism in detoxified methamphetamine abusers. Am J Psychiatry 158: 383-389.

Vollm BA, de Araujo IE, Cowen PJ, Rolls ET, Kringelbach ML, Smith KA et al (2004). Methamphetamine activates reward circuitry in drug naive human subjects. Neuropsychopharmacology 29: 1715-1722.

Wachtel SR, De Wit H (1999). Subjective and behavioral effects of repeated $d$-amphetamine in humans. Behav Pharmacol 10: 271-281.

Westerink BHC, Korf J (1976). Turnover of acid dopamine metabolites in striatal and mesolimbic tissue of the rat brain. Eur J Pharmacol 37: 249-255.

Wilson JM, Kalasinsky KS, Levey AI, Bergeron C, Reiber G, Anthony RM et al (1996). Striatal dopamine nerve terminal markers in human, chronic methamphetamine users. Nat Med 2: 699-703.

Zahniser NR, Sorkin A (2004). Rapid regulation of the dopamine transporter: role in stimulant addiction? Neuropharmacology 47: 80-91. 